\title{
A review of X-ray imaging phosphors
}

\author{
S V MOHARIL \\ Department of Physics, Nagpur University, Nagpur 440010, India \\ MS received 15 March 1993; revised 13 September 1993
}

\begin{abstract}
The important methods of $X$-ray imaging use various phosphors. The phosphors give light proportional to the amount of radiation. The light is emitted either as $\mathrm{X}$-ray excited fluorescence, phosphorescence, or due to stimulated, radiative recombinations of defects generated by X-ray exposures. The role of phosphors in improving image quality and reducing exposures to patients is important. Properties of various phosphors which can be used for $\mathrm{X}$-ray imaging applications are reviewed here.
\end{abstract}

Keywords. X-ray imaging; phosphors.

\section{Introduction}

Almost immediately after the discovery of X-rays by Röntgen, it was realized that this radiation is not very efficient in affecting photographic emulsions. A search for phosphors, which are able to convert $\mathrm{X}$-rays into visible radiation, was started. Pupin (as quoted by Brixner 1987) found that $\mathrm{CaWO}_{4}$ emits light upon X-ray incidence, which affects photographic film more effectively than the X-rays themselves. Several materials have since then been developed (Smets 1991). These will be reviewed under the section on screen phosphors. Later, more effective ways of X-ray detection and imaging using scintillators and photostimulatable phosphors were invented; these will be discussed in the subsequent sections.

\section{Screen phosphors}

\subsection{Mechanism}

High energy ionizing radiation in the form of X-rays is absorbed by the lattice and secondary charge carriers such as electron and hole pairs are created. After thermalization, these pairs recombine, and this process ultimately results in the emission of photons. Energy efficiency $\eta$ of the overall process is given (Robins 1980)

$$
\eta=\left(1-r_{b}\right) \frac{h v_{a}}{E} \eta_{t} Q
$$

where $r_{b}$ is the fraction of primary radiation scattered back, $h v_{a}$ the quantum emitted, $E$ the average energy to generate one $\mathrm{e}-\mathrm{h}$ pair, $\eta_{t}$ the efficiency for transfer of $\mathrm{e}-\mathrm{h}$ recombination energy to the activator, and $Q$ the quantum efficiency of luminescence centre. Practically, screen phosphors are characterized by their speeds given by

$$
S=A Q D,
$$

where $A$ is the absorption coefficient of phosphor and $D$ the detection efficiency 
defined as

$$
D=\int D_{\lambda} \phi d_{\lambda} / \int \phi d_{\lambda},
$$

where $D_{\lambda}$ and $\phi$ are sensitivity and flux respectively.

Screen phosphors should thus have high absorption of X-rays, high densities and stopping power, high luminescence efficiency, emission matching with the most sensitive range of the photographic materials $(300-480 \mathrm{~nm})$, not very long decay time $(\ngtr 1 \mathrm{~s})$, good radiation resistance, non-toxicity, good mechanical and chemical stability, etc.

Needless to say, a single material possessing all these characteristics has not been found, but compromising on some factor or the other, a phosphor can be found to suit the application.

\subsection{Materials}

2.2a $\mathrm{CaWO}_{4}$ : This is the earliest known phosphor, discovered by Edison (see Harvey 1957). Both excitation and emission take place in $\mathrm{WO}_{4}^{-}$group. Emission is at $430 \mathrm{~nm}$ giving a $D$ of $81 \%$. Of the constituent atoms only $\mathrm{W}(Z=74)$ gives dominant contribution to X-ray absorption. The energy efficiency is rather poor, being only about $5 \%$. Radiation resistance is also rather poor, but can be improved by adding $\mathrm{NaHSO}_{4}$ which introduces shallow traps which are emptied at RT itself.

Efforts were made to replace $\mathrm{CaWO}_{4}$ (Dutch patent 6917280, 1970; US patent 3,527,710, September 1970; Bates 1968; Ludwig 1972; Ludwig and Prener 1972; Stevels 1976). The materials have been systematically reviewed by Stevels and Pingault (1975). However, these materials were not found to be better than $\mathrm{CaWO}_{4}$, due to one drawback or the other, e.g. $\mathrm{ZnS}: \mathrm{Ag}$ is more sensitive than $\mathrm{CaWO}_{4}$ at lower energies but image is sharper with $\mathrm{CaWO}_{4}$. Better materials were found only after the seventies.

2.2b LaOBr:Re: LaOBr doped with rare earths (Tb, Tm or Dy) were studied by Blasse and Bril (1967). An X-ray screen using LaOBr:Ce, Tb was reported by Rabatin (1971). The method of preparation of the phosphor and more detailed properties were given by Holsa et al $(1980,1981)$.

2.2c $\mathrm{M}^{\prime} \mathrm{ReTaO} \mathrm{O}_{4}$ : Rare earth tantalates crystallize in two types of structures designated as $M$ type and $M^{\prime}$ type (Wolten 1967). Blasse and Bril (1970) studied $\mathrm{M}^{\prime} \operatorname{ReTaO}{ }_{4}$ for $\mathrm{Re}=\mathrm{Gd}, \mathrm{Y}$ and Lu. Application to X-ray screens is described by Brixner and Chen (1983). These compounds have high density $\left(7.56 \mathrm{~g} / \mathrm{cm}^{3}\right)$ and little afterglow. The excitation and emission is in $\mathrm{TaO}_{4}$ luminescence centre which is excited via charge transfer process. Emission is at $337 \mathrm{~nm}$ which is suitable for blue sensitive $\mathrm{X}$-ray films. When small quantities $(\simeq 2 \%)$ of $\mathrm{Nb}$ are incorporated, all the energy is transferred to niobate group emitting at $410 \mathrm{~nm}$. Energy efficiency is $9 \%$ and the detection efficiency $95 \%$.

2.2d $\mathrm{Gd}_{2} \mathrm{O}_{2} \mathrm{~S}: \mathrm{Tb}: \quad$ Rare earth oxysulphides doped with $\mathrm{Tb}$ were studied by Klassem and de Groot (1947) and Wickersheim et al $(1969,1970)$. They found $13 \%$ efficiency for La oxysulphide and $18 \%$ for the Gd compound. These materials also have high 
densities. Screens using these materials were made by Wang (1969) and Wang et al (1979). Buchanan et al (1972) and Stevels (1975) demonstrated the use of this phosphor using green sensitive films.

Lammers et al (1987) and Lammers and Blasse (1987) reported other Tb doped compounds such as $\mathrm{Gd}$ silicate and germanate which are suitable as screen phosphors.

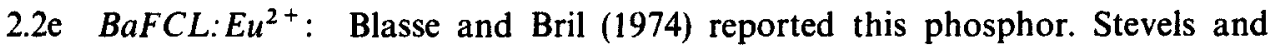
Pingault (1975) proposed its use for X-ray screens. It becomes more important in the context of photostimulatable phosphors which will be discussed later. Properties of various screen phosphors are given in table 1.

\section{Phosphors for computed tomography}

\subsection{X-ray scintillators}

In 1973, Housefield (1973) described a new technique for X-ray imaging. In this technique (computed tomography, CT), the recording of the image is electronic and not photographic. An array of detectors consisting of phosphors coupled with photodiodes replaces the screen. X-ray exposure produces 'scintillations' which originate in prompt recombinations of lattice defects produced by $\mathrm{X}$-rays. The photodiode current signals can be stored and processed. The use of photodiodes changes some of the requirements drastically. Green-yellow emitters are more suitable than the blue ones. Phosphors for X-ray detectors in CT are basically scintillators. There are some important differences in the requirements for these two types of phosphors. In scintillation detection of nuclear radiation, fast decay is important. If

Table 1. X-ray screen phosphors.

\begin{tabular}{|c|c|c|c|c|}
\hline Material & $\begin{array}{l}\text { Density } \\
\left(\mathrm{g} / \mathrm{cm}^{3}\right)\end{array}$ & $\begin{array}{c}\text { X-ray } \\
\text { attn. co-eff. } \\
\text { (at } 75 \mathrm{keV}) \\
\left(\mathrm{cm}^{-1}\right)\end{array}$ & $\begin{array}{l}\text { Conversion } \\
\text { efficiency }\end{array}$ & $\begin{array}{l}\text { Emission } \\
\text { (nm) }\end{array}$ \\
\hline $\mathrm{CaWO}_{4}$ & 6.06 & 3.83 & 6.5 & 440 \\
\hline $\mathrm{Zn}_{2} \mathrm{SiO}_{4}$ & & $1 \cdot 64$ & $11 \cdot 5$ & \\
\hline $\mathrm{ZnS}: \mathrm{Ag}$ & & 1.97 & $17 \cdot 0$ & \\
\hline $\mathrm{Zn}_{0.58} \mathrm{Cd}_{0.42} \mathrm{~S}: \mathrm{Ag}$ & & 4.6 & $14 \cdot 5$ & \\
\hline $\mathrm{Ba}_{2} \mathrm{SiO}_{5}: \mathrm{Pb}$ & & $6 \cdot 19$ & $3 \cdot 5$ & \\
\hline CsI:Tl & $4 \cdot 52$ & $11 \cdot 7$ & $10-0$ & 550 \\
\hline $\mathrm{La}_{2} \mathrm{O}_{2} \mathrm{~S}: \mathrm{Tb}$ & & $9 \cdot 2$ & $12 \cdot 5$ & 543 \\
\hline $\mathrm{Gd}_{2} \mathrm{O}_{2} \mathrm{~S}: \mathrm{Tb}$ & $7 \cdot 34$ & $8 \cdot 1$ & 13 & $414,440,543$ \\
\hline $\mathrm{LaOBr}: \mathrm{Ce}, \mathrm{Tb}$ & $7 \cdot 56$ & & & 543 \\
\hline $\mathrm{M}^{\prime} \mathrm{GdTaO}$ & $8 \cdot 55$ & $6 \cdot 1$ & & 490,543 \\
\hline $\mathrm{M}^{\prime} \mathrm{YTaO}_{4}$ & $7 \cdot 56$ & $4 \cdot 5$ & $9 \cdot 0$ & 337 \\
\hline $\begin{array}{l}\mathrm{Gd}_{3} \mathrm{Ga}_{5} \mathrm{O}_{12}: \mathrm{Tb} \\
\mathrm{Ba}_{3}\left(\mathrm{PO}_{4}\right)_{2}: \mathrm{Eu}^{2+}\end{array}$ & $7 \cdot 1$ & & & \\
\hline $\mathrm{CsI}: \mathrm{Na}$ & $4 \cdot 51$ & & $10 \cdot 0$ & 410 \\
\hline $\mathrm{BaFCl}: \mathrm{Eu}^{2+}$ & & & 13 & 385 \\
\hline $\mathrm{BaFBr}: \mathrm{Eu}^{2+}$ & & & 13 & 385 \\
\hline $\mathrm{BaSO}_{4}: \mathrm{Eu}^{2+}$ & & & 6 & 377 \\
\hline
\end{tabular}


there is a weak afterglow, it does not interfere with the detection of the next particle due to use of pulse height discrimination. For phosphors in X-ray CT, on the other hand, fast clearing of the screen is important, otherwise the afterglow will contribute to the noise in the next frame. Afterglow is thus totally undesirable for CT. On the other hand, the decay in CT phosphor has to be just fast enough to enable the scanning of the frame without interfering signal from the previous scan (fraction of a millisecond).

\subsection{Requirements}

Besides the 'low afterglow' CT phosphors should possess properties (Rossner and Grabmaier 1991; Ishii and Kobayashi 1991) such as high quantum or radiant conversion efficiency, emission in the range of photodiodes (green-red), rapid decay $(<0.1 \mathrm{~ms}$ ), low afterglow (intensity less than $5 \%$ of the maximum value in $2 \mathrm{~ms}$ ), high $\mathrm{X}$-ray absorption coefficient, high transmittance of the emitted light, high radiation resistance, chemical and thermal stability, etc.

\subsection{Materials}

Phosphors CsF, NaI:Tl, BGO and $\mathrm{CdWO}_{4}$ which are good scintillators are also good phosphors for CT applications. Besides these, CsI: Tl which is not efficient as a scintillator due to its green emission is suitable in CT for this very reason.

$\mathrm{ZnWO}_{4}$ and $(\mathrm{Y}, \mathrm{Gd})_{2} \mathrm{O}_{3}: \mathrm{Eu}$ are other candidates as $\mathrm{CT}$ phosphors. Properties of various materials have been frequently reviewed (Farukhi 1982; Grabmaier 1984; Holl et al 1988). These are summarized in table 2. It is seen that none of the phosphors is free from drawbacks. CsI:TI has the highest light output and emission matching with photodiode response, but it has a long afterglow. CsF, discovered by van Sciver and Hofstadter (1952), has low afterglow, but it is very hygroscopic. BGO has high $\mathrm{X}$-ray attenuation necessary for compact detector assembly and good resolution, but its light output is low. Growth and properties of the single crystals of these materials have been recently reviewed by Ishii and Kobayashi (1991).

\subsection{Recent developments}

In recent years, hot pressed, transparent ceramics in place of single crystals have been developed for use in CT. $(\mathrm{Y}, \mathrm{Gd})_{2} \mathrm{O}_{3}:$ Eu in such form was reported by Greskovich and coworkers (Greskovich et al 1985, 1986; DiBianca et al 1985; Cusano et al). $\mathrm{Gd}_{2} \mathrm{O}_{2} \mathrm{~S}: \mathrm{Pr}, \mathrm{Ce}, \mathrm{F}$ introduced by Yamada et al (1989) can be prepared by hot pressing techniques using $\mathrm{LiGeF}_{6}$ as a sintering agent (Ito et al 1988). It has emission at $520 \mathrm{~nm}$, density of $7.34 \mathrm{~g} / \mathrm{cm}^{3}$, good sensitivity and low afterglow $(0.01 \%$ after $3 \mathrm{~ms})$.

\section{Photostimulatable $X$-ray phosphors}

A new technique for X-ray imaging based on photostimulatable phosphors was described by Sonoda et al (1983). This allows the use of photomultiplier tubes (PMT) as detector instead of film (Takahashi et al 1985). 


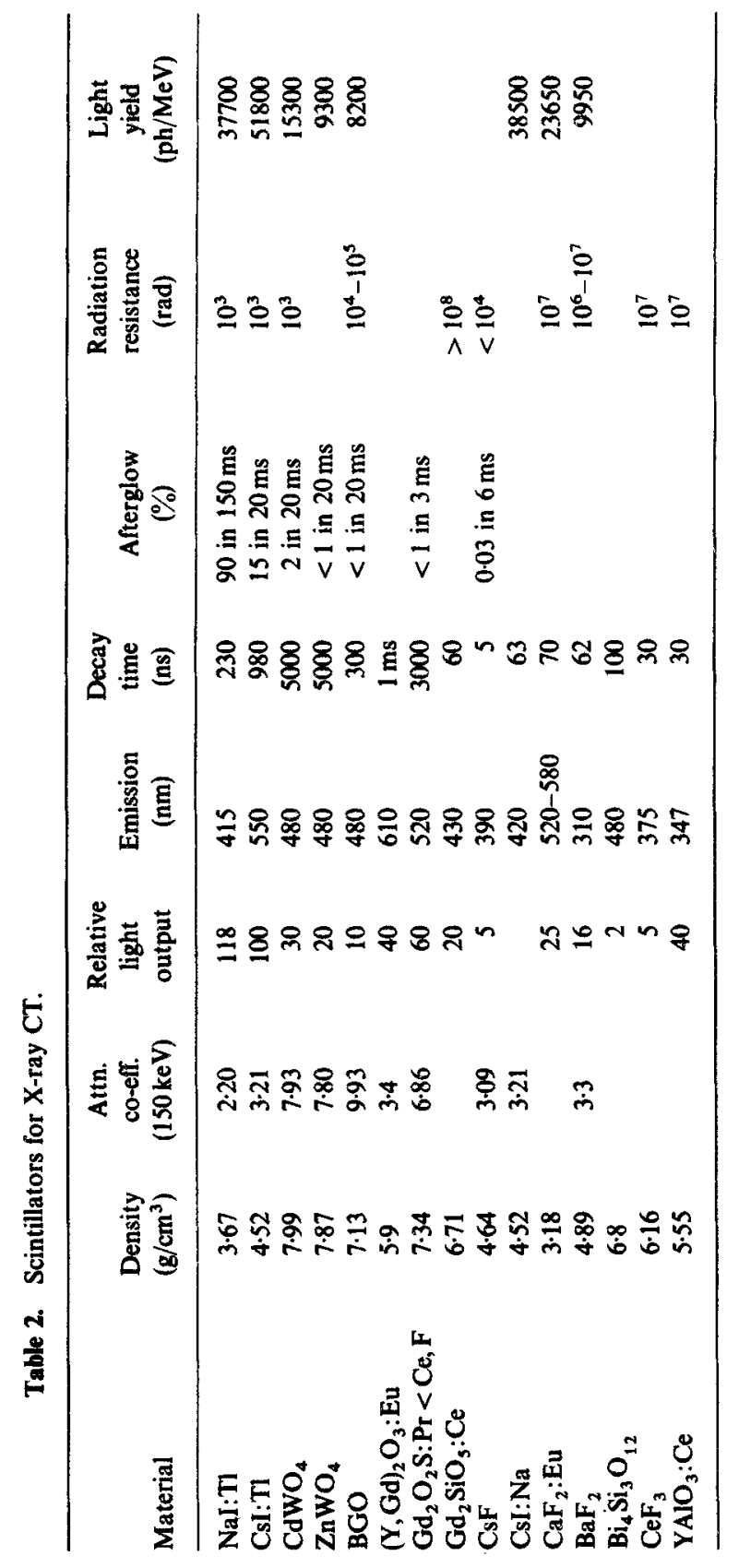


Exposure to X-rays produces electron and hole trapped defects in the photostimulatable X-ray phosphors. The photostimulation liberates electrons (or holes), which recombine with holes (or electrons). The recombination, directly or indirectly, leads to light emission.

Photostimulatable X-ray phosphors should have (von Seggern 1989; Crawford and Brixner 1991) efficient X-ray absorption; high light output; short lifetime $(<2 \mu \mathrm{s})$; low afterglow; optical stimulation spectrum in the range of commonly available, inexpensive lasers such as $\mathrm{He} / \mathrm{Ne}$ laser; emission in the range of PMT (violet-blue), well separated from the stimulating light; good transmission for emitted as well as stimulating light; dose linearity; reusability following read out or suitable optical erasure; low fading during the time lapse between exposure and read out.

\subsection{Materials}

Various types of materials have been considered for use as photostimulatable X-ray storage phosphors. These include alkali halides such as RbBr:Tl (Amitani et al 1986; von Seggern et al 1988a, 1989), CsI: Na (Brinkman 1965), alkaline earth halides doped with $\mathrm{Eu}^{2+}$ (Takahashi et al 1984; Takahashi and Miyahara 1988; Jianhu and Mianzeng 1988; Kano et al 1986; Iwabuchi et al 1991) or $\mathrm{Yb}^{2+}$ (Schipper and Blasse 1991), alkaline earth sulphides (Keller et al 1957; Gasiot et al 1982; Chakrabarti et al 1988), barium bromogermanate (Meijerink and Blasse 1991) or silicate (Garcia et al 1979, 1980; Meijerink and Blasse 1989b), or borate doped with $\mathrm{Eu}^{2+}$ (Meijerink and Blasse 1989a, 1990).

4.1a $R b B r: T l$ : Though RbBr:Tl phosphor was studied quite early (Inohara 1965; Sharan 1983), the photostimulation properties were studied only in 1986 (Amitani et al 1986). von Seggern et al (1989) proposed the following mechanism. The radiation creates $\mathrm{F}$ centres and $\mathrm{Tl}^{2+}$ centres. Photostimulation raises an $\mathrm{F}$ centre electron to the excited state, from which it tunnels to $\mathrm{Tl}^{2+}$ converting it to $\mathrm{Tl}^{+}$in excited state $\left({ }^{2} \mathrm{P}_{1},{ }^{3} \mathrm{P}_{0}\right)$. The light emission is obtained when $\mathrm{Tl}^{+}$returns to ground state $\left({ }^{1} \mathrm{~S}_{0}\right)$. In earlier works, they proposed that $\mathrm{Tl}^{2+}$-electron recombination is by transport of electron through conduction band (von Seggern et al 1988a). However, the observation that the temperature dependence of PSL was solely determined by lifetime of $\mathrm{Tl}^{+}$in the range $50-500 \mathrm{~K}$, and that there was no decrease in PSL below $80 \mathrm{~K}$ where release of electron into conduction band becomes less probable prompted them to propose the tunneling mechanism (von Seggern 1989; von Seggern et al 1989).

4.1b Sulphides: Infrared stimulatable phosphors based on sulphides and selenides had been known for a long time (e.g. see Fonda 1946; Garlick and Mason 1949; Keller et al 1957; for reviews see Mason 1965; Matsuoshi and Shinoya 1977). These phosphors could store energy for days and were used in wartime as light sources (Kroger 1947). A special session on these phosphors was held in the Cleveland meeting of the Optical Society of America on 7 March 1946. Use in IR detection was also proposed (Kunz and Urbach 1937).

The possibility of using these phosphors for X-ray storage, however, was indicated as late as 1982 (Gasiot et al 1982; Chakrabarti et al 1988). These phosphors, however, suffer from the drawback that they are sensitive to UV and visible light as well. 
4.1c $B a F X: E u^{2+}: \mathrm{BaFCl}: \mathrm{Eu}^{2+}$ was studied as early as 1974 (Blasse and Bril 1974), and its use for X-ray screens was proposed in 1975 (Stevels and Pingault 1975). BaFX: $\mathrm{Eu}^{2+}$ photostimulatable phosphors for CT were proposed by Takahashi et al (US Patent 4,239,968 and 4,236,078; Takahashi et al 1984, 1985). These workers also proposed the mechanism of luminescence in this phosphor. They suggested that creation of $\mathrm{F}$ centres by $\mathrm{X}$-rays due to filling of existing vacancies by electrons and the release of the trapped electron during photostimulation is involved in PSL. It was also speculated that during irradiation $\mathrm{Eu}^{2+}$ gets oxidized to $\mathrm{Eu}^{3+}$. Decrease in $\mathrm{Eu}^{2+}$ luminescence and increase in that of $\mathrm{Eu}^{3+}$ were observed (Takahashi et al 1984; de Leeuw et al 1987) which support the hypothesis. von Seggern et al (1988b) and von Seggern (1989) proposed that $F$ centre electron is not released but it tunnels to $\mathrm{Eu}^{3+}$. Close association of $\mathrm{F}$ centres and $\mathrm{Eu}^{3+}$ was suggested. The fact that the PSL lifetime has the same temperature characteristics as $\mathrm{Eu}^{2+}$ emission was taken as the supporting evidence. Later works refute $\mathrm{Eu}^{2+} \rightarrow \mathrm{Eu}^{3+}$ conversion (Meijerink and Blasse 1991; Hangleiter et al 1990; Crawford and Brixner 1991). In fact Sun and $\mathrm{Su}$ (1988) found evidence for $\mathrm{Eu}^{3+} \rightarrow \mathrm{Eu}^{2+}$ conversion. Instead of $\mathrm{Eu}^{3+}$, intrinsic hole trapping sites such as $V_{k}$ centres were suggested (Crawford et al 1989). Reuter et al (1990) suggested that irradiation creates $F$ centre interstitial pairs stabilized by $\mathrm{Eu}^{2+}$ at $\mathrm{Ba}$ substitutional sites. $\mathrm{F}$ centre stimulation destabilizes the interstitial halogen centre. Electron tunneling from $F$ centre converts the pair into $e+V_{k}$ pair which decays and the energy is transferred to nearby $\mathrm{Eu}^{2+}$ ion. Crawford and Brixner (1991) pointed out that only the samples fired in nitrogen/hydrogen atmosphere show PSL, and thus speculated that the hole trap is hydrogen anion at fluorine substitutional site. Upon photostimulation $F$ centre electron and hole recombine by tunneling and the energy of recombination is transferred to $\mathrm{Eu}^{2+}$.

\subsection{Recent developments}

In recent years Blasse and coworkers (Meijerink and Blasse 1989a, b, 1990, 1991; Schipper and Blasse 1991) studied several phosphors such as barium bromosilicate germanate, borate and $\mathrm{Eu}^{2+}$ doped $\mathrm{BaFX}$ all of which show promising properties. Systems $\mathrm{M}_{4} \mathrm{O}_{6} \mathrm{X}(\mathrm{M}=\mathrm{Ca}, \mathrm{Sr}$ or $\mathrm{Ba}$ and $\mathrm{X}=\mathrm{F}$ or $\mathrm{Cl})$ were also investigated (Schipper et al 1991). Properties of various photostimulatable phosphors are summarized in table 3 .

Table 3. Photostimulatable X-ray phosphors.

\begin{tabular}{llcccc}
\hline Phosphor & $\begin{array}{c}\text { Emission } \\
(\mathrm{nm})\end{array}$ & $\begin{array}{c}\text { Stimulation } \\
(\mathrm{nm})\end{array}$ & $\begin{array}{c}\text { Lifetime } \\
(\mathrm{ns})\end{array}$ & $\begin{array}{c}\text { Excitation } \\
\text { energy } \\
\left(\mu \mathrm{J} / \mathrm{mm}^{2}\right)\end{array}$ & $\begin{array}{c}\text { Conversion } \\
\text { efficiency } \\
\left(\mathrm{pJ} / \mathrm{mm}^{2} / \mathrm{mr}\right)\end{array}$ \\
\hline $\mathrm{RbBr}: \mathrm{Tl}^{+}$ & 370 & 700 & 280 & & \\
$\mathrm{BaFCl}: \mathrm{Eu}^{2+}$ & 385 & & & & \\
$\mathrm{BaFBr}_{\mathrm{Eu}^{2+}}$ & 385 & 600 & 750 & 40 & 2 \\
$\mathrm{Ba}_{5} \mathrm{SiO}_{4} \mathrm{Br}_{6}: \mathrm{Eu}^{2+}$ & 440 & 500,610 & 720 & 40 & 4 \\
$\mathrm{Ba}_{2} \mathrm{~B}_{5} \mathrm{O}_{9}{\mathrm{Br}: \mathrm{Eu}^{2+}}_{\mathrm{Ba}_{4} \mathrm{O}_{6} \mathrm{Br}: \mathrm{Eu}^{2+}}^{410,440}$ & 620 & & 300 & $0 \cdot 04$ \\
\hline
\end{tabular}




\section{Conclusions}

The new techniques of X-ray imaging such as computed tomography and photostimulation offer several advantages such as electronic storing and image processing, speed, high resolution, etc. over the conventional screens. It is seen from this survey that there are very efficient phosphors available for X-ray imaging. Use of these phosphors in conjunction with new techniques will reduce exposure and increase image quality a great deal. Considering that about $90 \%$ of exposure to man-made radiations arise from $X$-rays, such reduction will be desirable. On the other hand, implementation of the new techniques and the new phosphors is costly. Major X-ray imaging work is still done using $\mathrm{CaWO}_{4}$ screens, the earliest known imaging device. Future efforts may be directed at obtaining cheaper phosphors and techniques.

\section{Acknowledgement}

Financial support from the Atomic Energy Regulatory Board is gratefully acknowledged.

\section{References}

Amitani K, Kano A, Tsuchino H and Schimada F 1986 SPIE's conf, and exhibition: Electric imaging. 26th fall symp., printing of paper summaries, p. 180

Bates C W 1968 Elect. Ele. Phys. A28 951

Blasse G and Bril A 1967 Philips Res. Rep. 22481

Blasse G and Bril A 1970 J. Lum. 3109

Blasse G and Bril A 1974 J. Lum. 8502

Brinckman P 1965 Phys. Lett. 15305

Brixner L H 1987 Mater. Chem. Phys. 16253

Brixner L H and Chen H Y 1983 J. Electrochem. Soc. 1302435

Buchanan R A, Finklestein S I and Wickersheim K A 1972 Radiology 105187

Chakrabarti K, Mathur V K, Rhodes J E and Abbundi R J 1988 J. Appl. Phys. 641363

Crawford M K and Brixner L. H 1991 J. Lum. $48 \& 4937$

Crawford M K, Brixner L H and Somaiah K 1989 J. Appl. Phys. 663758

Cusano B A, Greskovich C D and DiBianca F A EU Patent 0097295

de Leeuw D M, Kovats T and Herko S P 1987 J. Electrochem. Soc. 134491

DiBianca F A, Georges J P J, Cusano B A and Greskovich C D 1985 US Patent 4525628

Farukhi M R 1982 IEEE Trans. Nucl. Sci. NS-29 1237

Fonda G R $1946 \mathrm{~J}$. Opt. Soc. Am. 35382

Garcia A, Latourretle B and Fausier C 1979 J. Electrochem. Soc. 1261734

Garcia A, Fausier C and Hagenmuller P 1980 C. R. Acad. Sci. 29033

Gariick G F and Mason D E 1949 Trans. Electrochem. Soc. 9690

Gasiot J, Braunlich P and Fillard J P 1982 Appl. Phys. Lett. 40376

Grabmaier B G 1984 IEEE Trans. Nucl. Sci. NS-31 372

Greskovich C D, Cusano B A and DiBianca F A 1985 US Patent 4518 546; 1986 US Patent 4517312

Hangleiter T, Koschnick F K, Spaeth J M, Nutall R H D and Eachus R S 1990 J. Phys. Cond. Mat. 26837

Harvey E N 1957 History of luminescence (Philadelphia: Am. Phil. Soc.)

Holl I, Lorenz E and Magera S 1988 IEEE Trans. Nucl. Sci. NS-35 105

Holsa J, Leskela M and Niinista L 1980 Thermochim. Acta 3579

Holsa J, Leskela M and Niinista L 1981 J. Solid State Chem. 37267

Housefield G N 1973 Br. J. Radiol. 461016

Inohara K 1965 Sci. Light 1492

Ishii M and Kobayashi M 1991 Prog. Cryst. Growth Charact. 23245

Ito Y, Yamada H, Yoshida M, Fujii H, Toda G, Takeuchi H and Tsukuda K 1988 Jpn. J. Appl. Phys. Letts. 27 L1371 
Iwabuchi Y, Umemoto C. Takahashi K and Shinoya 1991 J. Lum. $48 \& 49481$

Jianhu L and Mianzeng S 1988 J. Lum. $41 \& 42155$

Kano T, Takahashi T, Okajima K, Umetani K, Ataka S, Yokouchi H and Suzuki R 1986 Appl. Phys. Lett. 481117

Keller S P, Mapes J E and Cheroff G 1957 Phys. Rev. 108663

Klassem H A and de Groot W 1947 Philips Tech. Rev. 9321

Kroger F G 1947 Philips Tech. Rev. 9215

Kunz J and Urbach F 1937 US Patent 2074226

Lammers M J J and Blasse G 1987 J. Electrochem. Soc. 1342068

Lammers M J J, Severin J W and Blasse G 1987 J. Electrochem. Soc. 1342356

Ludwig G W 1972 J. Electrochem. Soc. 1181152

Ludwig G W and Prener J S 1972 IEEE Trans. Nucl. Sci. NS-19 3

Mason D E 1965 Rev. Mod. Phys. 37743

Matsuoshi T and Shinoya S 1977 J. Lum. 15201

Meijerink A and Blasse G 1989a J. Lum. 43283

Meijerink A and Blasse G 1989b Mater. Chem. Phys. 21261

Meijerink A and Blasse G $1990 \mathrm{~J}$. Lum. 471

Meijerink A and Blasse G 1991 J. Phys. D 24626

Rabatin J G 1971 US Patent 3617743

Reuter H H, von Seggern H, Reininger and Saile V 1990 Phys. Rev. Lett. 652438

Robins D J 1980 J. Electrochem. Soc. 1272694

Rossner W and Grabmaier B G 1991 J. Lum. 48 \& 4929

Schipper W J and Blasse G 1991 J. Solid State Chem. 94418

Schipper W J, Vroon Z A E, Blasse G, Schlein Th and Meyer G 1991 Mater. Chem. Phys. 3043

Sharan V B 1983 Phys. Status Solidi (b) 11641

Smets B M J 1991 in Advances in nonradiative processes in solids (ed.) B DiBartolo (New York: Plenum Press) p. 353

Sonoda M, Takano M, Miyahara J and Kato H 1983 Radiology 148833

Stevels A L N 1975 Medica Mundi 2012

Stevels A L N 1976 J. Lum. 12/1397

Stevels A L N and Pingault F 1975 Philips Res. Rep. 30277

Sun X and Su M 1988 J. Lum. 40/41 171

Takahashi K, Kohda K, Miyahara J, Kanemitsu Y, Amitani K and Shinoya S 1984 J. Lum. 31 \& 32266

Takahashi K, Miyahara J and Shibaraka Y 1985 J. Electrochem. Soc. 1321492

Takahashi K and Miyahara J 1988 Nature (London) 33689

Van Sciver M and Hofstadter R 1952 Phys. Rev. 87522

Von Seggern H 1989 Cryst. Latt. Def. Amorph. Mat. 18399

Von Seggern H, Voigt T and Schwarzmichel K 1988a Siemens Res. Dev. Rep. 17124

Von Seggern H, Voigt T, Knupter W and Lange G 1988b J. Appl. Phys. 641405

Von Seggern H, Meijerink A, Voigt T and Winnacker 1989 J. Appl. Phys. 664418

Wang S P 1969 IEEE NS symp, San Fransisco, USA

Wang $S$ P et al 1979 IEEE Trans. NS-17 49

Wickersheim K A, Alves R V and Buchanan R A 1969 USAEF 3rd Ann Rept.

Wickersheim K A, Alves R V and Buchanan R A 1970 IEEE Trans. Nucl. Sci. NS-17 57

Wolten G M 1967 Acta Crystallogr. 23939

Yamada H, Suzyki A, Uchida Y, Yoshida M and Yamamoto H 1989 J. Electrochem. Soc. 1362713 